\title{
BMJ Open Are there patient-related factors that influence sickness certification in patients with severe subjective health complaints? A cross-sectional exploratory study from different European countries
}

\author{
Suzanne L Merkus, ${ }^{1,2,3}$ Rob Hoedeman, ${ }^{4}$ Silje Mæland, ${ }^{1,5}$ \\ Kristel H N Weerdesteijn, ${ }^{2,3,6}$ Frederieke G Schaafsma, ${ }^{2,3,6}$ Maud Jourdain, ${ }^{7}$ \\ Jean-Paul Canevet, ${ }^{7}$ Cédric Rat, ${ }^{7}$ Johannes R Anema, ${ }^{2,3,6}$ Erik L Werner ${ }^{1,8}$
}

To cite: Merkus SL, Hoedeman R, Mæland S, et al. Are there patient-related factors that influence sickness certification in patients with severe subjective health complaints? A cross-sectional exploratory study from different European countries. BMJ Open 2017;7:e015025. doi:10.1136/ bmjopen-2016-015025

- Prepublication history for this paper is available online To view these files please visit the journal online (http://dx.doi. org/10.1136/bmjopen-2016015025).

Received 7 November 2016 Revised 24 May 2017 Accepted 12 June 2017

CrossMark

For numbered affiliations see end of article.

Correspondence to

Suzanne L Merkus; sImerkus@ gmail.com

\section{ABSTRACT}

Objectives To develop hypotheses about whether there are patient-related factors that influence physicians' decision-making that can explain why some patients with severe subjective health complaints (SHCs) are more likely to be granted sick leave than others.

Design Exploratory cross-sectional.

Setting Assessments of patient-related factors after watching nine authentic video recordings of patients with severe SHC from a Norwegian general practice. Our previous study showed that three of these nine patients were less likely than the remaining six patients to be granted sick leave by physicians from five European countries.

Participants In total, 10 assessors from Norway, the Netherlands and France.

Outcomes The direction in which the assessments may contribute towards the decision to grant a sickness certificate (increasing or decreasing the likelihood of granting sick leave).

Results Physicians consider a wide variety of patientrelated factors when assessing sickness certification. The overall assessment of these factors may provide an indication of whether a patient is more likely or less likely to be granted sick leave. Additionally, some single questions (notable functional limitations in the consultation, visible suffering, a clear purpose for sick leave and psychiatric comorbidity) may indicate differences between the two patient groups.

Conclusions Next to the overall assessment, no notable effect of the complaints on functioning and suffering, a lack of a clear purpose for sick leave and the absence of psychiatric comorbidity may be factors that could help guide the decision to grant sick leave. These hypotheses should be tested and validated in representative samples of professionals involved in sickness certification. This may help to understand the tacit knowledge we believe physicians have when assessing work capacity of patients with severe SHC.
Strengths and limitations of this study

- Hypotheses were developed based on the assessment of patient-related factors that were retrieved from the scientific literature.

- The nine video vignettes used to assess the patientrelated factors are all authentic consultations that provide realistic case stories for the assessments.

- The video vignettes provided the opportunity to assess non-verbal communication which is an important aspect of realistic assessments.

- The assessors were not blinded for the results of the previous study: they knew which three patients were less likely than the remaining six patients to be granted sick leave.

- This exploratory study is small regarding both assessors and cases.

\section{INTRODUCTION}

Sick-listing patients with severe subjective health complaints (SHC) can be difficult and demanding for physicians. ${ }^{1}$ Severe SHC are characterised by symptoms such as joint pain, fatigue, irritable bowels, numbness and sleep disturbances that are medically unexplained as they lack objective pathology. ${ }^{2}$ The lack of objective pathology complicates the sick-leave assessments by physicians, as the sick-leave assessments are to a large extent based on the patient's self-evaluation. ${ }^{134}$

For a sick note, most European countries require a physician's assessment of the patient's functional capacity based on a specific medical diagnosis, but severe SHC are also often recognised as legal reasons for being incapable of work. ${ }^{5-8}$ However, physicians report that the lack of objective pathology in patients with 
severe SHC can make them uncertain whether the patient really has a disease that merits a sickness certificate. ${ }^{1}$ In such situations, trust in the patient's self-evaluation becomes very important. ${ }^{1}$ This suggests that compared with conditions where cause of disease and disability are medically objectionable, such as a broken leg or heart attack, the assessment of sickness certification in patients with severe SHC is more strongly based on other factors than the biomedical diagnosis and functional capacity alone.

Among the factors that have been reported to influence sickness certification in patients with severe SHC are patient-related factors. These factors include the patient's ability to evoke empathy, the patient's attitude towards returning to work and whether a period of sick leave has a clear purpose. ${ }^{1}$ Additional factors are related to the physician, for example, personal experience with illness and a tendency to avoid conflict. ${ }^{1}$ Both physician and patient-related factors are examples of insights gained through experience as a practising physician. These insights may not always be explicit; they could be considered tacit knowledge. ${ }^{4910}$ Tacit knowledge is the type of knowledge that the 'knower cannot tell', but through awareness it can become explicit. ${ }^{11}$

Making tacit knowledge of patient-related factors explicit may help understand the findings from our recent study in which physicians from five European countries assessed sick leave of patients with severe SHC. ${ }^{12}$ All physicians assessed the same nine video vignettes of a doctor's consultations with nine of his patients with severe SHC. Despite differences in culture, legislation and physician characteristics, the physicians across the countries and specialisations agreed to a large extent which of the nine patients should be granted sick leave and which should not. ${ }^{12}$ Consistently, the same three patients were granted sick leave less often by the physicians, even though all patients reported severe SHC. The question arises why these three patients were granted sick leave less often than the remaining six patients; reasons for this may be provided by patient-related factors.

Making tacit knowledge regarding patient-related factors more explicit would contribute towards a broader understanding of the mechanisms of sickness certification. For physicians this could contribute towards more knowledge of the patient-related factors that play a role in sickness certification assessments as well as more awareness around their own decision-making processes. This in turn would contribute towards more equal assessments between patients with severe SHC. This paper aimed to develop hypotheses about whether there are patient-related factors that influence physicians' decision-making that can explain why some patients with severe SHC are more likely to be granted sick leave than other patients with severe SHC.

\section{METHODS}

Materials and procedure

In this exploratory study, the 10 coauthors of this research paper independently assessed nine video vignettes of patients with severe SHC. The video vignettes were the same ones we used in our previous study (see table 1 for a description of each patient). ${ }^{12} 13$ The videos showed nine authentic consultations between a Norwegian general practitioner and patients with severe SHC. The original recordings were transcribed verbatim and re-recorded with professional actors in the patients' roles. Each vignette started with a short introduction by the general practitioner with some background information and results of medical investigations. With exception of SM and SLM, the authors are physicians: general practitioners, occupational physicians or insurance physicians in Norway, France and the Netherlands. SM is a physiotherapist and associate professor in occupational therapy and SLM is an occupational health researcher.

Figure 1 depicts our previous study's findings: patients 2, 6 and 9 were less likely to be granted sick leave than the remaining six patients by all participating physicians from the five European countries. ${ }^{12}$ To assess how patients 2, 6 and 9 differed from the remaining ones, all coauthors of the present study assessed all nine patients for patient-related factors using predefined questions.

\section{Patient-related factors}

Patient-related factors that could influence physicians' decision-making regarding sickness certification in patients with severe SHC were retrieved from the literature. PubMed was searched by combining each of the search terms 'sickness certification', 'sick note', 'sick listing', 'sick leave', with each of the search terms 'decision' and 'assessment'. Additionally, references of relevant articles were searched. ${ }^{14}$ We included published articles from peer-reviewed journals into our study that were written in the English language and that were about patient-related factors that may influence physicians' sick leave decisions in consultations with patients with SHC. We excluded articles that were about: (1) patient-related factors in patients without SHC, (2) physician-related factors that may influence the sick leave decision and (3) factors related to the interaction between physician and patient, because the video vignettes did not permit any interaction. One author (SLM) screened all the titles and abstracts of the search results, and retrieved and evaluated the full text articles of those titles and abstracts that were thought to be relevant for this study. In total, 1245 titles and abstracts were found in PubMed and screened for inclusion. Out of these, 28 full text articles were retrieved and screened. Finally, six articles were included into the study.

Nine factors were identified from the included articles that could be appraised for the video vignettes: functional ability, ${ }^{15} 16$ ability to evoke empathy, ${ }^{13}$ cognitions and behaviour, ${ }^{17}$ coping style, ${ }^{3}{ }^{17}$ secondary gain, ${ }^{17}$ expectation for a sick note, ${ }^{18}$ social situation, ${ }^{3} 18$ a clear purpose of sick leave ${ }^{13}$ and psychiatric comorbidity. ${ }^{3}{ }^{17}$ A further three patient-related factors were identified in the included articles; however, they could not be assessed with the video vignettes and were therefore excluded. 
Table 1 Description of the patients presented in the video vignettes ${ }^{1213}$

\begin{tabular}{|c|c|c|c|}
\hline Vignette & Gender, age & Demography & Complaints \\
\hline 1 & $F, 25$ & $\begin{array}{l}\text { Single, no children } \\
\text { Interrupted secondary education } \\
\text { Currently in rehabilitation programme } \\
\text { Several short-term jobs and sick leave spells }\end{array}$ & $\begin{array}{l}\text { Generalised, wide spread pain } \\
\text { Neck and back pain } \\
\text { Anxiety and depression } \\
\text { Respiratory complaints }\end{array}$ \\
\hline 2 & $\mathrm{M}, 40$ & $\begin{array}{l}\text { Married, two children } \\
\text { Works offshore an on oil platform } 2 \text { weeks on, } \\
4 \text { weeks off } \\
\text { Several shorter periods of sick leave and two } \\
\text { long spells }\end{array}$ & $\begin{array}{l}\text { Neck and back pain } \\
\text { Sleep disturbances due to pain } \\
\text { Irritable bowel syndrome }\end{array}$ \\
\hline 3 & $F, 53$ & $\begin{array}{l}\text { Housewife for } 20 \text { years with five foster-care } \\
\text { children in addition to two biological children } \\
\text { Foster care has ended, and consequently her } \\
\text { income too } \\
\text { No formal education or work experience outside } \\
\text { the home }\end{array}$ & $\begin{array}{l}\text { Generalised, wide spread pain } \\
\text { Anxiety } \\
\text { Fatigue }\end{array}$ \\
\hline 4 & M, 37 & $\begin{array}{l}\text { Married, unknown number of children } \\
\text { Used to work offshore but started as self- } \\
\text { employed in construction }\end{array}$ & $\begin{array}{l}\text { Severe fatigue } \\
\text { Economic burden due to loss of work capacity }\end{array}$ \\
\hline 5 & $M, 42$ & $\begin{array}{l}\text { Married, three children } \\
\text { Works as a formwork carpenter } \\
\text { No previous history of sick leave }\end{array}$ & $\begin{array}{l}\text { He feels physically and mentally exhausted } \\
\text { Has a 12-year-old daughter with serious } \\
\text { behavioural problems who is enrolled in a } \\
\text { behavioural training programme with great } \\
\text { demands of parents' involvement } \\
\text { Afraid that he might collapse } \\
\text { No energy left to deal with his daughter after } \\
\text { work }\end{array}$ \\
\hline 8 & M, 36 & $\begin{array}{l}\text { Married, two small children } \\
\text { Works as a teacher at comprehensive level } \\
\text { Active sports trainer, coaches a first division } \\
\text { handball team } \\
\text { No sick leave history, no previous psychiatric or } \\
\text { somatic disorder } \\
\text { Worries about possible serious illness despite } \\
\text { negative examinations }\end{array}$ & $\begin{array}{l}\text { Unspecific pain in jaw muscle, then the neck, } \\
\text { head and the stomach }\end{array}$ \\
\hline 9 & M, 38 & $\begin{array}{l}\text { Married, no children } \\
\text { Works as a technician at an event bureau } \\
\text { producing big shows, theatres and films } \\
\text { Commutes } 270 \mathrm{~km} \text { weekly for work }\end{array}$ & $\begin{array}{l}\text { General tiredness from work and } \\
\text { commuting and low energy } \\
\text { According to his wife, he is irritable and } \\
\text { passive, even aggressive towards her }\end{array}$ \\
\hline
\end{tabular}

F, female; M, male.

These factors were extensive prior knowledge via good familiarity with the patient ${ }^{115}$; detailed knowledge of the patient's work tasks ${ }^{16}$ and the motivation of the patient to return to work. ${ }^{17}$ A 10 th factor was added based on coauthors' expert opinion, the International Classification of Functioning, Disability and Health (ICF) and Dutch guidelines which concerned congruence of symptoms with medical causes, other's judgement and/or literature or guidelines. ${ }^{8} 19$ Based on the descriptions of the patient-related factors given in the relevant articles and 


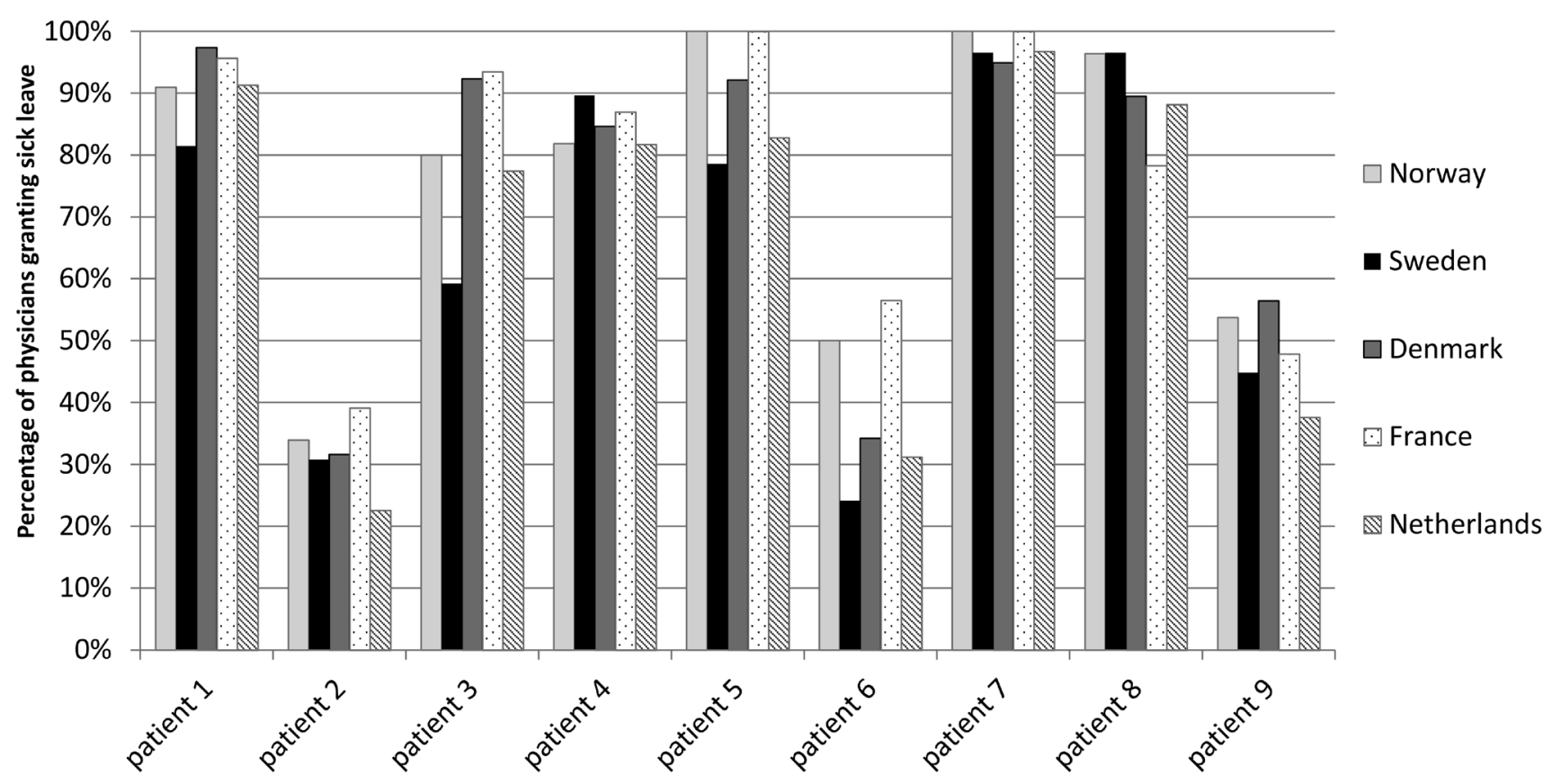

Figure 1 Percentage of general practitioners from Norway, Sweden, Denmark and France, and occupational and insurance physicians from the Netherlands granting sick leave to patients $1-9 .{ }^{12}$

guidelines, we developed 15 questions for which answers were given as yes or no. See online supplementary appendix I for the questions.

\section{ETHICAL APPROVAL}

The video vignettes used in the present study were first used in the study by Maeland $e t a l^{13}$ for which the Regional Committee for Medical and Health Research Ethics, Western Norway (REC West) assessed the study. The Committee concluded that because the study did not include individual health information, approval was not necessary. All patients consented to the use of their original consultation for the purpose of education and research. Information that could identify the patient in the vignettes was excluded or rewritten. Additionally, anonymity was maintained through the use of professional actors in the video vignettes.

\section{DATA ANALYSIS}

Among the patients from our previous study, we explored differences in patient-related factors between those who were least likely to be granted sick leave (ie, patients 2 , 6 and 9) and those who were most likely to be granted sick leave (ie, patients 1, 3, 4, 5, 7 and 8). ${ }^{12}$ First, the yes/no answers on the questions were recoded into answers that would increase or decrease the likelihood for granting sick leave. For example, reduced functional ability was hypothesised to increase the likelihood for granting sick leave, while a good coping style was hypothesised to reduce the likelihood. See online supplementary appendix II for how we recoded the responses to the questions. Second, the assessments were examined to identify whether any specific question could distinguish the patients with a lower likelihood of being granted sick leave from those with a higher likelihood of being granted sick leave. A question was considered to distinguish the two patient groups from each other when more assessors appraised patients 1,3, 4, 5, 7 and 8 than patients 2, 6 and 9 in a direction that would increase the likelihood of granting sick leave. We examined the assessments for all assessors $(\mathrm{n}=10)$ and for the physicians only $(\mathrm{n}=8)$.

\section{RESULTS}

All 10 coauthors of this research paper assessed the 15 questions for each of the nine patients; therefore, each patient had a total of 150 possible assessments. However, some answers were missing: six patients missed between one and three answers. Missing answers were not replaced, because they were considered to indicate that a question was not clearly formulated or difficult to answer for these patients.

\section{Distinguishing factors}

Table 2 provides an overview of the fraction of the 10 assessors who appraised each patient in the direction that would increase the likelihood of granting sick leave. Per question, the fraction of assessors appraising the questions in the direction of granting sick leave varied between $0 / 10$ and $10 / 10$. For each individual question, the fraction of assessments for at least one of the patients 2, 6 or 


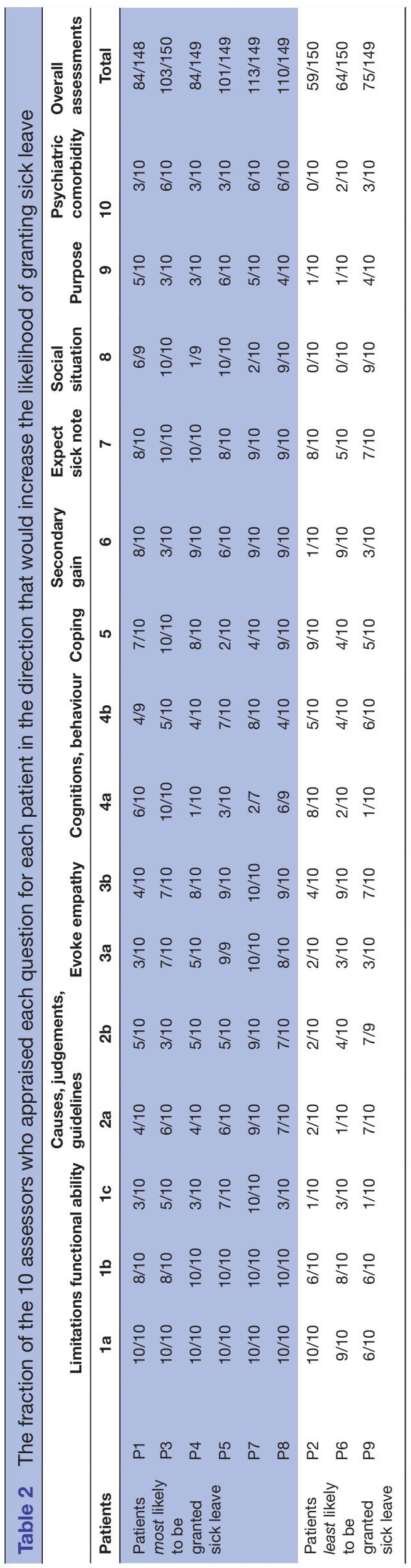

9 was equal to or higher than the fraction of assessments of at least one of the remaining patients 1, 3, 4, 5, 7 and 8 . Therefore, patients who were least likely to be granted sick leave (patients 2, 6 and 9) could not be distinguished from those who were mostlikely to be granted sick leave (patients 1, 3, 4, 5, 7 and 8) based on a single question or factor, or a set of questions or factors. Including the assessments of the physicians only did not change the results meaningfully.

Although we could not distinguish between the patients based on specific questions or factors, some trends were identified that could potentially suggest differences between the patients. The first trend is seen when considering the overall assessments per patient: patients 2, 6 and 9 were less often assessed in the direction that would increase the likelihood of granting sick leave (59-75 out of the 150 assessments) compared with patients 1, 3, 4, 5, 7 and 8 (84-113 out of the 150 assessments). Additional trends are seen for individual questions. For patients 2, 6 and 9 , fewer assessors tended to perceive the patients to have notable functional limitations in the consultation (question 1c) (1-3 out of 10 assessors) compared with the remaining patients (3-10 out of 10 assessors). Fewer assessors tended to perceive patients 2, 6 and 9 to be suffering in the consultation (question 3a) (2-3 out of 10 assessors) compared with the remaining patients (3-10 out of 10 assessors). For patients 2, 6 and 9 fewer assessors tended to see a clear purpose for sick leave (question 9) (1-4 out of 10 assessors) compared with the remaining patients (3-6 out of 10 assessors). Fewer assessors tended to appraise patients 2, 6 and 9 to have psychiatric comorbidity (question 10) (0-3 out of 10 assessors) compared with the remaining patients (3-6 out of 10 assessors).

\section{DISCUSSION}

To gain more insight into the tacit knowledge of physicians who are responsible for sickness certification, this research paper aimed to generate hypotheses about whether patient-related factors that influence physicians' decision-making could explain why some patients with severe SHC are more likely to be granted sick leave than others. This was done with a novel approach consisting of a literature search and assessments of video vignettes based on patient-related factors found in the literature search. The literature search showed that physicians consider a wide variety of patient-related factors when assessing sickness certification. Trends in the overall assessment of these factors may provide an indication of whether a patient is more likely or less likely to be granted sick leave. Additionally, trends in four questions suggested some differences between the two patient groups. These questions were notable functional limitations in the consultation, visible suffering, a clear purpose for sick leave and psychiatric comorbidity.

The decision to grant sick leave depends on a variety of factors, including the social security scheme and legislation, physician-related factors, the complex interaction 
between patient and physician, as well as patient-related factors. ${ }^{132021}$ Regarding the latter, this study supports several previous studies indicating that in the process of sickness certification in patients with severe SHC, physicians take into account a variety of patient-related factors. ${ }^{13} 151618$ This suggests, similar to these previous studies, that physicians take into account other factors than only those related to legislation. However, to our knowledge, the relevance of these other factors in the decision-making process has not been previously studied. Our study suggests that patient-related factors may help understand why some patients with severe SHC are granted a sick note while others are not. It may be helpful to physicians and other stakeholders to understand such mechanisms.

In this study, we could not identify a specific factor, or a set of factors, that could clearly distinguish patients who were least likely to be granted sick leave from the patients who were most likely to be granted sick leave. For all patients, the assessments of the individual questions seemed highly individual and based on the patient's unique characteristics, for example his/her complaints, functional ability, family situation, personality and coping in relation to work demands. This supports the understanding that patients with severe SHC are a heterogeneous group regarding symptoms, potential causes, private life situation and possible treatment/therapy that no single question or factor may fully cover. ${ }^{2}$

However, some trends were found in the data for which hypotheses can be developed about why some patients with severe SHC may be more likely than others to be granted sick leave. The first trend was identified for the overall assessments: even though the assessments differed between the patients for individual questions, the overall assessments reflected whether a patient was more likely or less likely to be granted sick leave.

Additional trends were found in four questions. Two of these questions were related to notable limitations in the consultation and visible suffering of the patient. These trends suggest that sick leave may have been granted less willingly to three of the patients, because the effects of the complaints were not evident during the consultation. The other two questions were related to a clear purpose for sick leave and psychiatric comorbidity. These two trends suggest that sick leave may have less readily been granted to three of the patients, because the purpose of sick leave was more often considered to be unclear and they were less often assessed to have a secondary psychiatric diagnosis. Therefore, next to the overall assessment, no notable effects of the complaints on functioning and suffering, a lack of a clear purpose for sick leave, and the absence of psychiatric comorbidity may potentially be factors that could help guide the decision to grant sick leave. ${ }^{13415}$

\section{Strengths and limitations}

This study had some strengths and limitations. A strength of the study was the use of patient-related factors found in the literature in the assessments of patient cases. To our knowledge, this is the first study to generate hypotheses based on the systematic exploration of tacit knowledge of patient-related factors in patients with severe SHC. Additionally, in our previous study, the physicians had different specialisations and came from different European countries; this cultural and professional diversity was also reflected in the assessors of the present study. Furthermore, the nine video vignettes used in the material are authentic consultations providing realistic case stories for the assessments. Moreover, the video vignettes made it possible to assess the subjective nature of some of the patient-related characteristics through non-verbal communication; this is an important aspect of realistic assessments.

This exploratory study also has some limitations. First, assessors were not blinded for the results of the previous study when assessing the videos. They knew that patients 2, 6 and 9 were less likely than the remaining six patients to be granted sick leave by the participating physicians from the five European countries in our previous study. This information bias could have influenced the assessments. Second, not all assessors were medical doctors who are trained to assess patients; however, this did not influence the results. Third, our data are exploratory and small regarding both assessors and cases; therefore, the generalisability of the study findings is limited. Additionally, the questions we developed to assess the video vignettes contain some weaknesses. Some questions may have had some overlap; for example, solving a psychosocial problem at home (question 8) is sometimes a secondary gain (question 6), and it was not taken into account that physicians may weigh some questions more heavily than others. Furthermore, a small amount of data was missing for six patients; however, that was so limited that it did not influence the results of the study. Lastly, we excluded some patient-related factors retrieved from the literature, because they could not be assessed with the video vignettes; these excluded factors could have been important aspects of physicians' tacit knowledge. These factors were extensive prior knowledge via good familiarity with the patient ${ }^{115}$; detailed knowledge of the patient's work tasks ${ }^{16}$ and the motivation of the patient to return to work. ${ }^{17}$ Additionally, it is possible that we missed some patient-related factors by restricting our search to one database, that is, PubMed. Such patient-related factors could have been different factors all together or factors that are mediated by patient complaints or coping.

\section{Practical implications}

This research paper suggests that a variety of patient-related factors can be considered by physicians when assessing work capacity of patients with severe SHC. In practice, it is unlikely that all factors are considered by all physicians or that physicians consider them similarly. Therefore, some variation between physicians will exist that may translate into variations in their sick leave decisions. In our previous study, there was little variation 
between countries regarding sickness certification practices; however, some variation was seen between physicians. For example, for patient 2, approximately $30 \%$ of the physicians would grant sick leave, while approximately $70 \%$ would not do so. ${ }^{12}$ More equality between consultations may be reached when physicians know which factors to assess. These factors may be taught to medical students and physicians. ${ }^{22}$ Variation between physicians may also be reduced by further developing the questions used in the present study as a guidance in consultations when assessing sick leave in patients with severe SHC. ${ }^{23}$ From our study some relevant factors emerged that can be tested in future research.

\section{FUTURE RESEARCH}

The methods in this study are exploratory to study patient-related factors that may influence physicians' decision-making regarding sick leave and are meant for generating hypotheses that should be tested in representative samples of professionals. The four hypotheses that can be tested are: sick leave is less likely to be granted to patients with severe SHC when (1) the assessment of patient-related factors overall are in the direction that reduces the likelihood of granting sick leave; (2) the effects of the complaints on functioning and suffering are not visible during the consultation; (3) the purpose of sick leave is unclear and (4) the patient does not have psychiatric comorbidity. Additionally, future research may improve the questions developed in this study. The missing data, together with feedback from the assessors, imply that some questions may have been challenging to assess. Examples of these questions regard cognitions and behaviour, the social situation and knowing what an effective coping style or secondary gain entail. For future research, we suggest that the questions considered in this study are developed further, that is, they are made clearer, and it is assessed whether some factors may be given more weight and whether other questions need to be added. In a different research design such added questions include those excluded from this study, that is, extensive prior knowledge via good familiarity with the patient, detailed knowledge of the patient's work tasks and the motivation of the patient to return to work. With improved questions, a similar study with patient vignettes could be replicated to test the developed hypotheses found in the present study in a larger sample of physicians who are blinded to the previous study's outcome.

\section{CONCLUSION}

In conclusion, the methods of this study are exploratory and were meant to generate new hypotheses about patient-related factors that influence physicians' sick leave decision-making. The study showed that a variety of patient-related factors are considered by physicians when assessing sickness certification for patients with severe SHC. The assessments of patients with severe SHC were highly individual depending on the patient's characteristics, including their symptoms, functional ability, their cognitions and behaviours, and private life situation. However, in our sample, the decision not to grant sick leave to three patients may have been guided by the overall assessment of factors related to the patient, by the lack of notable effect of the complaints on functioning and suffering in the consultation, by the lack of a clear purpose for sick leave and/or by the absence of psychiatric comorbidity. These hypotheses should be tested in representative samples of professionals. Making this tacit knowledge more explicit may contribute towards more equal assessments of sick leave in patients with severe SHC.

\section{Author affiliations}

${ }^{1}$ Research Unit for General Practice, Uni Research Health, Bergen, Norway ${ }^{2}$ Department of Public and Occupational Health, VU University Medical Centre, Amsterdam, The Netherlands

${ }^{3} \mathrm{EMGO}+$ Institute for Health and Care Research, Amsterdam, The Netherlands ${ }^{4}$ Department of Science, ArboNed Occupational Health Services, Utrecht, The Netherlands

${ }^{5}$ Department of Occupational Therapy, Physiotherapy and Radiography, Bergen University College, Bergen, Norway

${ }^{6}$ Research Center for Insurance Medicine, AMC-UMCG-UWV-VUmc, Amsterdam, The Netherlands

${ }^{7}$ Department of General Practice, Faculty of Medicine, University of Nantes, Nantes, France

${ }^{8}$ Department of General Practice, Institute of Health and Society, University of Oslo, Oslo, Norway

Contributors SLM conducted the literature search. SLM, ELW and RH developed the questions. SLM was responsible for the data analysis. All authors assessed the nine video vignettes, revised the manuscript critically for important intellectual content and approved the final version to be published.

Funding The study was funded by the Norwegian Labour and Welfare Administration through the FARVE program.

\section{Competing interests None declared.}

Patient consent Detail has been removed from this case description/these case descriptions to ensure anonymity. The editors and reviewers have seen the detailed information available and are satisfied that the information backs up the case the authors are making.

Provenance and peer review Not commissioned; externally peer reviewed.

Data sharing statement There are no other unpublished data available from this study.

Open Access This is an Open Access article distributed in accordance with the Creative Commons Attribution Non Commercial (CC BY-NC 4.0) license, which permits others to distribute, remix, adapt, build upon this work non-commercially, and license their derivative works on different terms, provided the original work is properly cited and the use is non-commercial. See: http://creativecommons.org/ licenses/by-nc/4.0/

(C) Article author(s) (or their employer(s) unless otherwise stated in the text of the article) 2017. All rights reserved. No commercial use is permitted unless otherwise expressly granted.

\section{REFERENCES}

1. Nilsen S, Werner EL, Maeland S, et al. Considerations made by the general practitioner when dealing with sick-listing of patients suffering from subjective and composite health complaints. Scand $J$ Prim Health Care 2011;29:7-12.

2. Burton $\mathrm{C}$. Beyond somatisation: a review of the understanding and treatment of medically unexplained physical symptoms (MUPS). Br J Gen Pract 2003;53:231-9.

3. Aamland A, Malterud K, Werner EL. Phenomena associated with sick leave among primary care patients with medically unexplained 
physical symptoms: a systematic review. Scand J Prim Health Care 2012;30:147-55.

4. Wainwright $\mathrm{E}$, Wainwright $\mathrm{D}$, Keogh $\mathrm{E}$, et al. The social negotiation of fitness for work: tensions in doctor-patient relationships over medical certification of chronic pain. Health 2015;19:17-33.

5. Socialstyrelsen. Försäkringsmedicinskt beslutsstöd - vägledning för sjukskrivning. [Medical insurance decisions - guidlines for sickness certification]. Edita Västra Aros AB 2016. Cited3 November]; Available from www.socialstyrelsen.se.

6. Lovdata Lov om folketrygd (folketrygdloven). Del IV. Ytelser ved sykdom m.m. Kapittel 8. Sykepenger [Social security law. Part IV. Sickness benefits a.0. Chapter 8. Sick leave pay] 2016. Cited3 November]; Available from https://lovdata.no/ dokument/NL/lov/1997-02-28-19/KAPITTEL_5-4\#KAPITTEL_5-4.

7. Ziektewet. (2016, 1 July). [Cited 20163 November]; Available from: http://wetten.overheid.nl/BWBR0001888/2016-0701\#AfdelingTweede

8. Landelijk Instituut Social Verzekering (LISV). Medisch arbeidsongeschiktheidscriteruim - richtlijn [Medical work disability criteria - guideline]. Tijdelijk instituut coordinatie en afstemming 1996 www.nvvg.nl.

9. Turner S, Higginson J, Oborne CA, et al. Codifying knowledge to improve patient safety: a qualitative study of practice-based interventions. Soc Sci Med 2014;113:169-76.

10. Nicolini D, Powell J, Conville P, et al. Managing knowledge in the healthcare sector. A review. Int J Manag Rev 2008;10:245-63.

11. Eraut M. Non-formal learning and tacit knowledge in professional work. Br J Educ Psychol 2000;70 (Pt 1:113-36.

12. Werner EL, Merkus SL, Mæland S, et al. Physicians' assessments of work capacity in patients with severe subjective health complaints: a cross-sectional study on differences between five european countries. BMJ Open 2016;6:e011316.

13. Maeland S, Werner EL, Rosendal M, et al. Sick-leave decisions for patients with severe subjective health complaints presenting in primary care: a cross-sectional study in Norway, Sweden, and Denmark. Scand J Prim Health Care 2013;31:227-34.

14. Greenhalgh T, Peacock R. Effectiveness and efficiency of search methods in systematic reviews of complex evidence: audit of primary sources. BMJ 2005;331:1064-5.

15. Wahlström R, Alexanderson K. Chapter 11. Physicians' sick-listing practices. Scand J Public Health 2004;32:222-55.

16. Krohne K, Brage S. How GPs in Norway conceptualise functional ability: a focus group study. Br J Gen Pract 2008;58:850-5.

17. Dekkers-Sánchez PM, Wind H, Sluiter JK, et al. What factors are most relevant to the assessment of work ability of employees on long-term sick leave? the physicians' perspective. Int Arch Occup Environ Health 2013;86:509-18.

18. Werner EL, Côté P, Fullen BM, et al. Physicians' determinants for sick-listing LBP patients: a systematic review. Clin J Pain 2012;28:364-71.

19. World Health Organization. International classification of functioning, disability and health (ICF. Geneva, Switzerland, 2001a.

20. Byrne P, Ring A, Salmon P, et al. Tussles and rollovers: negotiating Sickness Certification in Primary Care. Adv Appl Sociol 2014;04:247-60.

21. Salmon P, Dowrick CF, Ring A, et al. Voiced but unheard agendas: qualitative analysis of the psychosocial cues that patients with unexplained symptoms present to general practitioners. $\mathrm{Br} J$ Gen Pract 2004;54:171-6.

22. Heiberg Engel PJ, Engel PJH. Tacit knowledge and visual expertise in medical diagnostic reasoning: implications for medical education. Med Teach 2008;30:e184-e188.

23. Gerner U, Alexanderson K. Issuing sickness certificates: a difficult task for physicians: a qualitative analysis of written statements in a swedish survey. Scand J Public Health 2009;37:57-63. 